Antonyuk Anastasia

Dragomanov National Pedagogical University

The Institute of Corrective Pedagogy and Psychology, student

\title{
HELPING SOMEONE WITH AN EATING DISORDER
}

\begin{abstract}
This article is devoted to describing of eating disorders. The aim of the article is to provide the reader some materials on researches of this problem in the society. The authors characterize the most common eating disorders and give some examples of dramatic life-stories telling some ill people.
\end{abstract}

Key words: eating disorders; anorexia, bulimia; binge eating disorder; anorexia athletic; orthorexia; teenagers, children, women.

1. Introduction. The most common eating disorders are anorexia, bulimia, binge eating disorder, anorexia athletica, orthorexia [3;9].

Anorexia: people with anorexia starve themselves out of an intense fear of becoming fat. Despite being underweight or even emaciated, they never believe they're thin enough. In addition to restricting calories, people with anorexia may also control their weight with exercise, diet pills, or purging. Anorexia Nervosa obsessing with controlling food intake $[3 ; 9 ; 4]$.

Bulimia involves a destructive cycle of bingeing and purging. Following an episode of out-of-control binge eating, people with bulimia take drastic steps to purge themselves of the extra calories. In order to avoid weight gain they vomit, exercise, fast, or take laxatives. Another words, Bulimia Nervosa - cycles of bingeing and purging driven by a desire to regulate feelings and worries and control body weight and shape. Purging can be: vomiting, intake of laxatives, enemas or diuretics, over exercises, restricting [7; 3; 9].

Binge Eating Disorder: people with binge eating disorder compulsively overeat, rapidly consuming thousands of calories in a short period of time. Despite feelings of guilt and shame over these secret binges, they feel unable to control their behavior or stop eating even when uncomfortably full. Another words, Binge Eating Disorder - eating excessive amounts of food at one time in order to make up for long periods of restricting/dieting AND/OR to comfort one's self or numb feelings [7; 3; 9]. Although anorexia and bulimia are very similar, people with anorexia are usually very thin and underweight but those with bulimia may be a normal weight or even 
overweight. Binge eating disorders, food phobia, and body image disorders are also becoming increasingly common in adolescence.

Anorexia Athletica - a condition where one over-exercises because he/she believes this will control his/her body and given him/her a sense of power, control and self-respect. (usually includes restricting food as well) [3].

Orthorexia - a cluster of food and weight related symptoms such as eating only 'healthy' foods, relying only on 'natural' foods and products (including when treating illness), and finding more pleasure in eating 'correctly' than in simply eating.

Night-Eating Syndrome - limiting eating during the day (restricting) and then compensating (by overeating) at night [9].

II. The aim of work is to investigate theoretical material and to study researches on this theme.

\section{To achieve the aim we have defined such tasks:}

1. To analyze and to learn the theoretical material on the topic.

2. To describe the variety of eating disorders .

3. To give some recommendations how can help someone with eating disorder.

III. The Results. It is interesting to describe myths about Eating Disorders: Myth 1: You have to be underweight to have an eating disorder. People with eating disorders come in all shapes and sizes. Many individuals with eating disorders are of average weight or are overweight. Myth 2: Only teenage girls and young women are affected by eating disorders. While eating disorders are most common in young women in their teens and early twenties, they are found in men and women of all ages. Myth 3: People with eating disorders are vain. It's not vanity that drives people with eating disorders to follow extreme diets and obsess over their bodies, but rather an attempt to deal with feelings of shame, anxiety, and powerlessness. Myth 4: Eating disorders aren't really that dangerous. All eating disorders can lead to irreversible and even life-threatening health problems, such as heart disease, bone loss, stunted growth, infertility, and kidney damage. $[6 ; 7 ; 10]$.

Many kids - particularly adolescents - are concerned about how they look and can feel self-conscious about their bodies. This can be especially true when they are going through puberty, and undergo dramatic physical changes and face new social pressures. Unfortunately, for a number of kids and teens, that concern can lead to an obsession that can become an eating disorder.

The causes of eating disorders aren't entirely clear. However, a combination of psychological, genetic, social, and family factors are thought to be involved.

For kids with eating disorders, there may be a difference between the way they see themselves and how they actually look. People with anorexia or bulimia often 
have an intense fear of gaining weight or being overweight and think they look bigger than they actually are. Also, certain sports and activities (like cheerleading, gymnastics, ballet, ice skating, and wrestling) that emphasize certain weight classes may put some kids or teens at greater risk for eating disorders [5].

Many kids who develop an eating disorder have low self-esteem and their focus on weight can be an attempt to gain a sense of control at a time when their lives feel more out-of-control. It can be a challenge for parents to tell the difference between kids' normal self-image concerns and warning signs of an eating disorder. While many kids and teens - girls in particular - are self-conscious, compare themselves with others, and talk about dieting, this doesn't necessarily mean they have eating disorders. Kids with eating disorders show serious problems with their eating and often have physical signs $[5,4]$.

The kids with an eating disorder will react defensively and angrily when confronted for the first time. In addition to the health problems, kids who have an eating disorder are probably not having much fun. They tend to pull away from friends and keep to themselves, avoiding going out for pizza with their friends, for example, or enjoying a birthday party.

If child has an eating disorder but he or she denies anything is wrong, book an appointment with their pediatrician or family doctor, or ask a school counselor, religious leader, or trusted friend to help. Often kids find it easier to admit that they have a problem to someone outside of their immediate family. A doctor will also be able to determine if there are any signs of the serious health problems associated with an eating disorder [7].

Parents can help prevent kids from developing an eating disorder by building their self-esteem and encouraging healthy attitudes about nutrition and appearance. If you become worried that your son or daughter might be developing an eating disorder, it's important to step in and seek proper medical care. At a time of great societal concern about obesity, it can be tricky for parents to talk with their kids about their eating habits. It's best to emphasize health, rather than weight. Make sure your kids know you love them for who they are, not how they look. [5, 4].

BBC documentary which follows the progress of 12-year-old Natasha and 13year-old Naomi through their treatment at Rhodes Farm, a residential clinic which treats children with anorexia nervosa. Filmed over four months, the film intimately depicts their painful struggle to overcome their obsessive relationship with food and their weight [1].

The HBO documentary film focuses on four young women struggling with anorexia: Brittany, a 15 year-old who strives to be thin to gain acceptance among her peers, and whose mother has also suffered with the disease; Shelly, 25, who has been battling anorexia for six years, and who enters Renfrew with a feeding tube surgically implanted in her stomach; Alisa, 30, a divorced mother of two who struggled for decades with a relentless compulsion to purge; and Polly, 29, who has spent years in and out of treatment and often challenges the Center's policies and procedures. The camera follows these women to places most have never ventured: one-on-one and group therapy sessions, emotionally wrought mealtimes, early morning weigh-ins, 
heated arguments with staff, and tense encounters with family members. In following their stories, we come to learn that each woman's fight for recovery is unique. Some will sabotage their own treatment; others will make significant strides; and still others will make progress only to discover that their insurance will not cover the long-term care they need to truly get well. What emerges is a portrait of an illness that is frustrating in its complexity and devastating in the pain it inflicts on its sufferers and those who care for them. Unflinching and incisive, THIN offers an experiential and emotional journey through the world of eating disorders and, ultimately, provides a greater understanding of their complexity: that they are not simply about food or body image or self-esteem, but a tangle of personal, familial, cultural and mental health issues [8].

The film An Anorexic's Tale: The Brief Life of Catherine brings attention to eating disorders, when many people didn't bring attention to it. Over a seven-year period, Catherine Dunbar underwent a terrible transformation. The teenager, unhappy with her weight, began a cycle of binging on food, then using laxatives to eliminate what she ate. Her battle with anorexia is shown in reenactments, as the once-pretty young woman descends into a nightmare of weight loss. An Anorexic's Tale: The Brief Life of Catherine traces her diary entries, as her family and doctors try in vain to bring her back. The program comes with a warning regarding its grim content, and parents are advised to view it before letting younger children watch [2].

Kids with eating disorders often react defensively and angrily when confronted for the first time. Many have trouble admitting, even to themselves, that they have a problem. Sometimes getting a family member or friend who has been treated for an eating disorder can help encourage someone to get help. A fear of being fat or overweight is a core problem for anyone with an eating disorder. So it's understandable that kids with eating disorders don't want to go to a clinic and "get fat."

Trying to help when someone doesn't think he or she needs it can be hard. Still, getting the professional assistance needed, even if your child resists, is essential. Enlist help from friends and family that your son or daughter trusts and loves people known to have your child's best interests at heart.

This child may be more receptive to a conversation if you focus on your own concerns and use "I" statements rather than "you" statements. For example, steer clear of statements like "you have an eating disorder" or "you're too thin," which may only prompt anger and denial. Instead, try "I'm worried that you have lost so much weight so quickly." Cite specific things the child has said or done that have made you worry, and explain that you will be scheduling a doctor's appointment to put your own mind at ease $[5,5]$.

In conclusion, Michelle New says for all: "Try to avoid power struggles regarding food - if your teen wants to "go vegetarian," be supportive even if you're an avid meat-eater. Teens frequently go through trendy eating periods, so try to set good limits, encourage healthy eating, and avoid fighting over food issues. Kids can catch on pretty quickly if their parents panic over one skipped meal. Try to gain perspective and talk to your kids about what's going on if they don't want to eat with the family", take an active role in creating a healthy lifestyle for your 
family. Involve your kids in the preparation of healthy, nutritious meals. Let them know that it's OK to eat when hungry and refuse food when they're not. Also, make exercise a fun, rewarding, and regular family activity.

\section{Bibliography}

1. Anorexic Teenage Girls (BBC Documentary) (Video) [Web site]. - Access mode: http://www.youtube.com/watch?v=RVFatHbLrN8

2. An Anorexic's Tale: The Brief Life of Catherine (Film, Thames TV movie, 1988, producer Allan Horrox, director Michael Whyte) [Web site]. - Access mode: http://www.youtube.com/watch?v=qAVq5icM-GY

3. Bersaglio Lauren. Types of Eating Disorders - National Eating Disorders Awareness (Video) [Web site]. - Access mode: http://www.youtube.com/watch?v=SQwT2JozBnM

4. Documentary: Anorexia Nervosa. The Irrational Fear Of Gaining Weight [Web site]. - Access mode: http://www.youtube.com/watch?v=jroyY5ICr14

5. New Michelle, Eating Desorders [Web site]. - Access mode: http://kidshealth.org/parent/emotions/feelings/eating_disorders.html

6. SAUWS Myth Busting Mondays - Eating Disorders (Video) [Web site]. - Access mode: http://www.youtube.com/watch?v=RrYTC7gmWTM

7. Smith Melinda. Helping someone with an eating disorder / Melinda Smith, Lawrence Robinson, Jeanne Segal : Last updated: December 2013. [Web site]. Access mode: http://www.helpguide.org/mental/eating_disorder_self_help.htm

8. Thin (full / HQ) (film) [Web site]. - Access mode: http://www.youtube.com/watch?v=v7E3aWXz7dE

9. 3 Types of Eating Disorders (Mental Health Guru) (Video) [Web site]. - Access mode: http://www.youtube.com/watch?v=isb2W1_8Urk

10. 20 Misconceptions/Myths About Eating Disorders (Video) [Web site]. - Access mode: http://www.youtube.com/watch?v=b06sHxJgo4w 